\title{
REPRODUCTIVE EFFICIENCY AND SITE ATTACHMENT OF TREE SWALLOWS AND MOUNTAIN BLUEBIRDS
}

HAROLD W. PINEL, 1017 - 19th Avenue N.W., Calgary, Alberta, T2M $0 Z 8$.

In March of 1973, 191 bird houses were erected as the initial phase of the Calgary Bluebird Trail. The number of nest boxes was doubled in 1974 to 382 , and since 1975,400 bird houses have been maintained. The trail is approximately 352 kilometers in length with the boxes being about 0.8 kilometers apart. The exact route of the trail is illustrated by Pinel and Robinson. ${ }^{10}$

Prior to 1973, personal observations indicated that Mountain Bluebirds maintained a fairly stable population in the badlands along the Red Deer River northeast of Calgary in the vicinity of Drumheller and Brooks, but west of Calgary in the foothills area, fewer Mountain Bluebirds were being seen during the nesting season as the years passed by. Tree swallows, like the bluebirds, were fairly common on migration, but during the nesting season, they were observed uncommonly as local pairs inhabiting the edge of Aspen or mixed White Spruce-Aspen woods in close proximity to a lake or slough in the foothills region. Pairs of Tree Swallows were also noted infrequently in Calgary, always near a nest box. More small acreages began to dot the landscape as the years passed, and with them came more buildings, more cultivation and more Starlings and House Sparrows. These visual assessments, plus the fact that other groups of people throughout the Prairie Provinces were concerned about the population of Mountain Bluebirds led the author to initiate a trail for the Calgary area.

Table 1 summarizes the reproductive data for the Bluebird Trail from 1973 through 1978. These figures are a compilation of the annual data as recorded by Pinel et al. ${ }^{9 \cdot 14}$ In its first year of operation, 1973, an astonishing $85 \%$ of the available nesting boxes were occupied. From 1975 through 1978 with the trail consisting of a constant 400 boxes, the occupancy rate varied only $3.8 \%$. This fact, plus an average 6-year occupancy rate of $92.8 \%$, illustrated a constant high demand for nesting boxes. This is further verified by the 1974 breeding data as compared to 1973. In 1974, the number of bird houses erected was exactly double that erected in 1973 - to see if the number of nests would double. The result was that the number of nests increased 2.2 times from 157 to 353 . In two 4-year studies, Chapman lists the occupancy rate varying from $62.5 \%$ to $84.5 \%$ in Massachusetts, while Houston gives the rate varying from $65 \%$ to $98.7 \%$ near Saskatoon, Saskatchewan. ${ }^{6}$ The availability of nest sites as a factor limiting the population size of Tree Swallows and Mountain Bluebirds has been documented by Chapman, ${ }^{1}$ Erskine, ${ }^{3}$ Holroyd, ${ }^{5}$ Von Haartman, ${ }^{4}$ and Whittle. ${ }^{16}$

Reproductive efficiency is the 


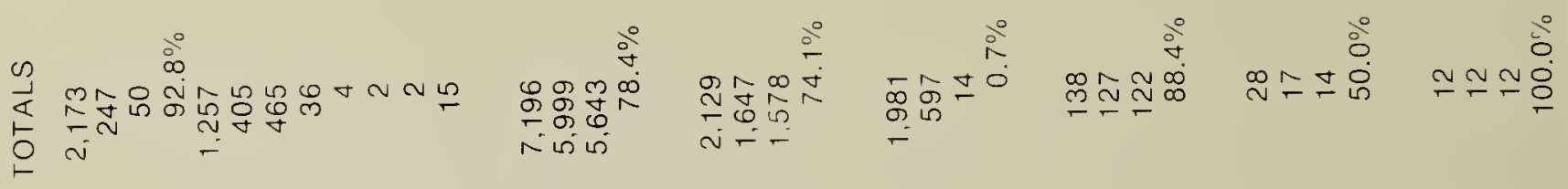

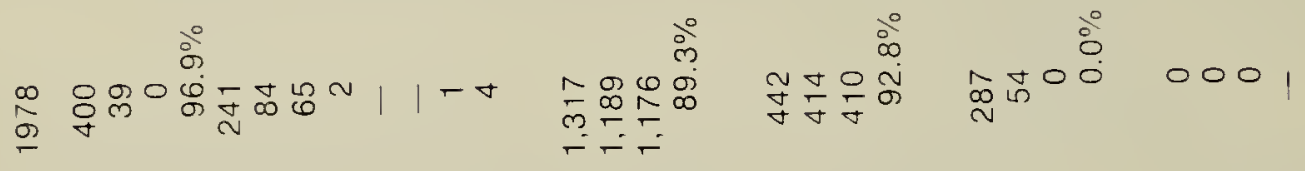

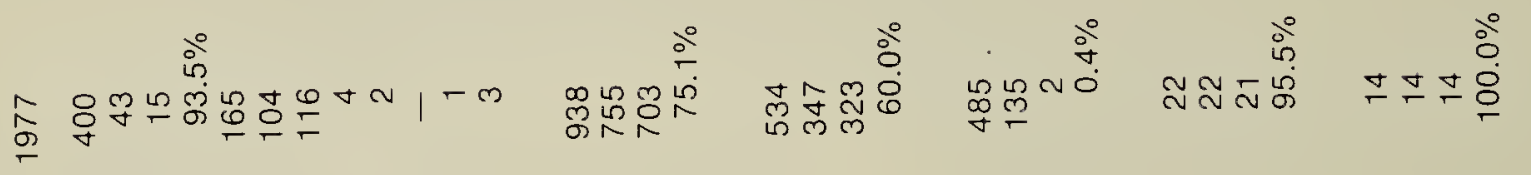

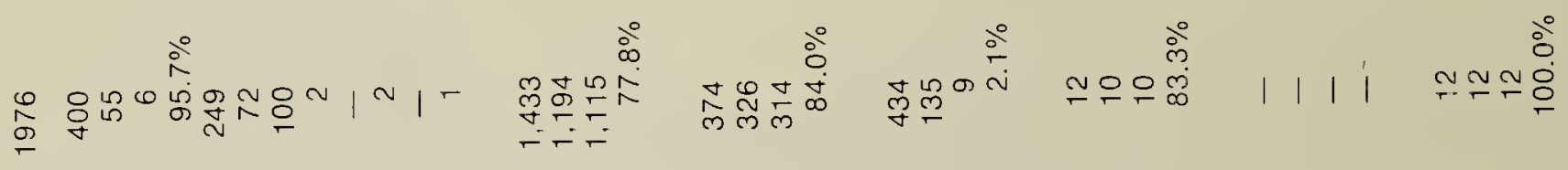

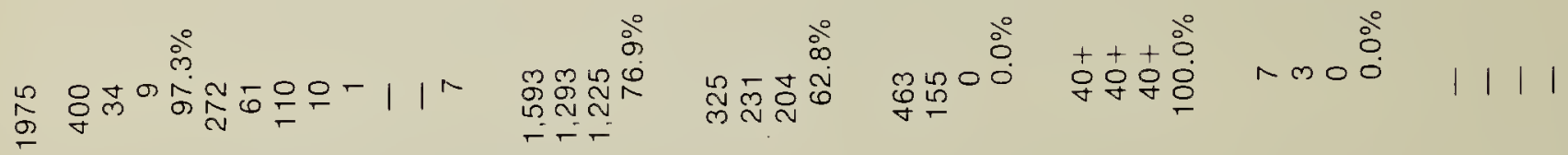

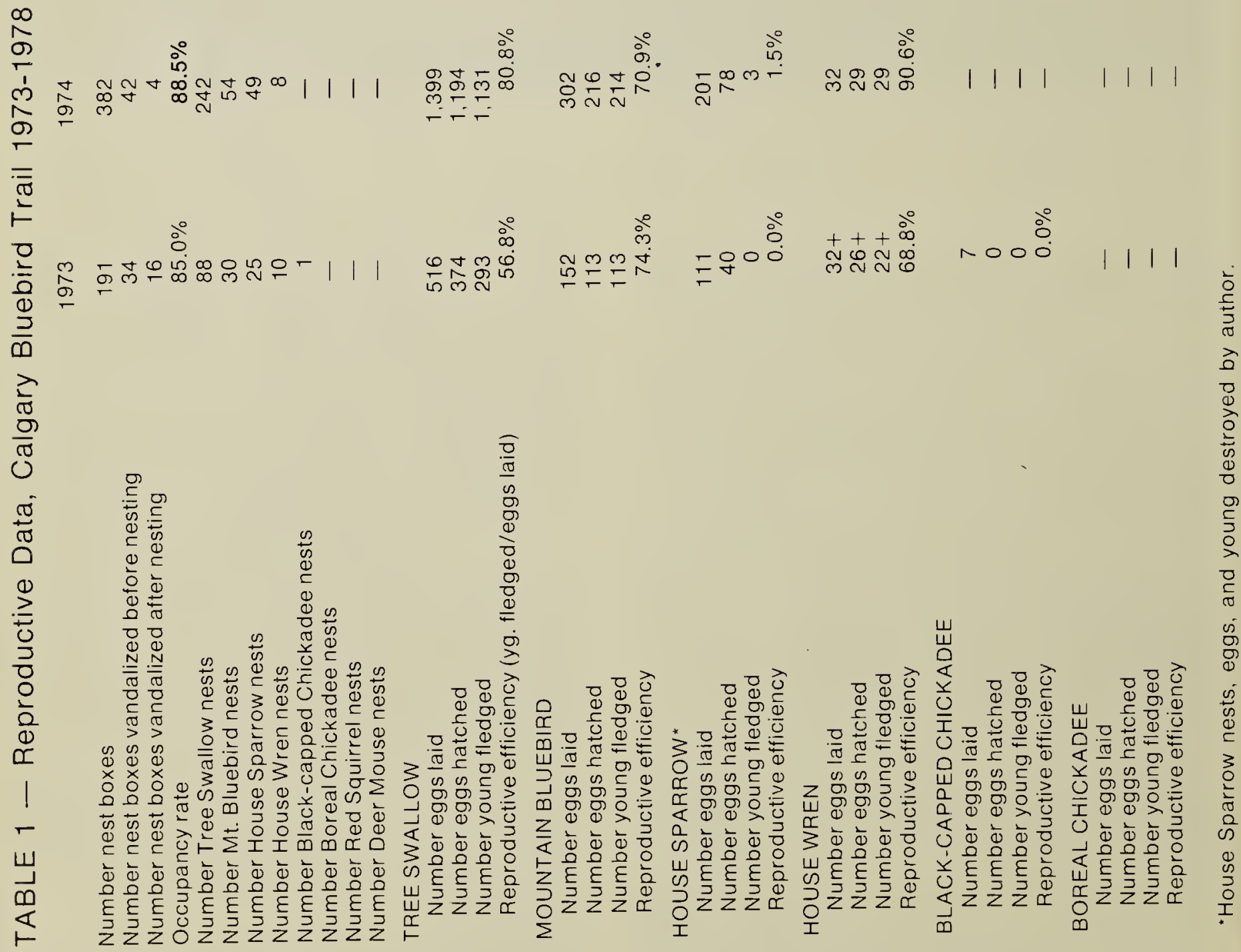


percentage of eggs producing fledged young. The 6-year mean reproductive efficiency for Tree Swallows and Mountain Bluebirds was $78.4 \%$ and $74.1 \%$, respectively. The slight difference in efficiency of the two species over the 6-year period was probably the result of a greater number of second broods by the bluebirds. In a number of cases, a female bluebird would lay a second clutch of eggs, but would desert them before hatching occurred. Other data on reproductive efficiency of Tree Swallows comes from Low who over a 3-year period recorded efficiencies varying from $38 \%$ to $58.6 \%$, and Chapman who recorded efficiencies from $51.5 \%$ to $84 \%$ over a similar 3 year period. ${ }^{81}$

Throughout the length of the trail, the habitat varies from cultivated land to native grassland to Aspen Parkland. Tree Swallows nested anywhere along the trail but Mountain Bluebirds were restricted to Aspen Parkland. House Sparrows preferred to nest in boxes located in areas of cultivated land or in boxes located near human habitation or man-made structures. Because of the melding of the different habitat types, and the apparent nonrestrictive habitat needs of Tree Swallows and House Sparrows, interspecific competition for nest boxes was prevalent. There were 191 occurrences of nesting by different species in the same bird house. Of these 191 occurrences, Tree Swallows were involved in 172 instances, House Sparrows in 104 instances, and Mountain Bluebirds in 87 instances. The two major trends observed in Table 2 were Tree Swallows occupying nesting boxes after House Sparrows and after Mountain Bluebirds. The reasons for both trends are quite different. In the case of the House Sparrows, it was the result of the author destroy- ing all attempts at nesting by the sparrows, while in the case of the bluebirds, it was the result of the Tree Swallows waiting until the Mountain Bluebirds had reared their family before they commenced nesting. In Figure 1, it can be seen that up to 1975, all three species increased their number of nests due to an increase in nesting boxes, but from 1975 to 1978 when the number of nesting boxes was constant, some species increased, while others decreased.

Tree Swallows and Mountain Bluebirds were banded during 1976 and 1977. In 1976, 609 swallows and 84 bluebirds were banded, and in 1977,410 swallows and 258 bluebirds were banded. Banding was done as opportunities arose and time permitted. Nestlings were banded from the time that they started to feather. Most of the adults were banded when they were incubating, or when they were feeding young more than 3 or 4 days old. After the young are half grown, it is more difficult to trap the adult birds because the young can reach up to the hole in the box, thereby eliminating the need for the parents to enter it. Table 3 summarizes banding and retrapping data.

The percentage of adult Tree Swallows retrapped was $13.7 \%$ as compared to $1.3 \%$ for those banded as nestlings. This ratio of approximately 10.5 to 1 adults to nestlings retrapped is even more interesting when you consider that only 197 adults were banded as compared to 822 nestlings. In a 14-year study of this species, Chapman found similar results. ${ }^{2}$ The percentages of adult swallows returning one year after they were banded varied from $7 \%$ to $55 \%$ and averaged $39.6 \%$. The percentages of banded nestlings returning the next year varied from $0 \%$ to $5.0 \%$ and averaged $2.4 \%$. 
Figure 1. Comparison of the annual number of Mountain Bluebird, Tree Swallow and House Sparrow nests.

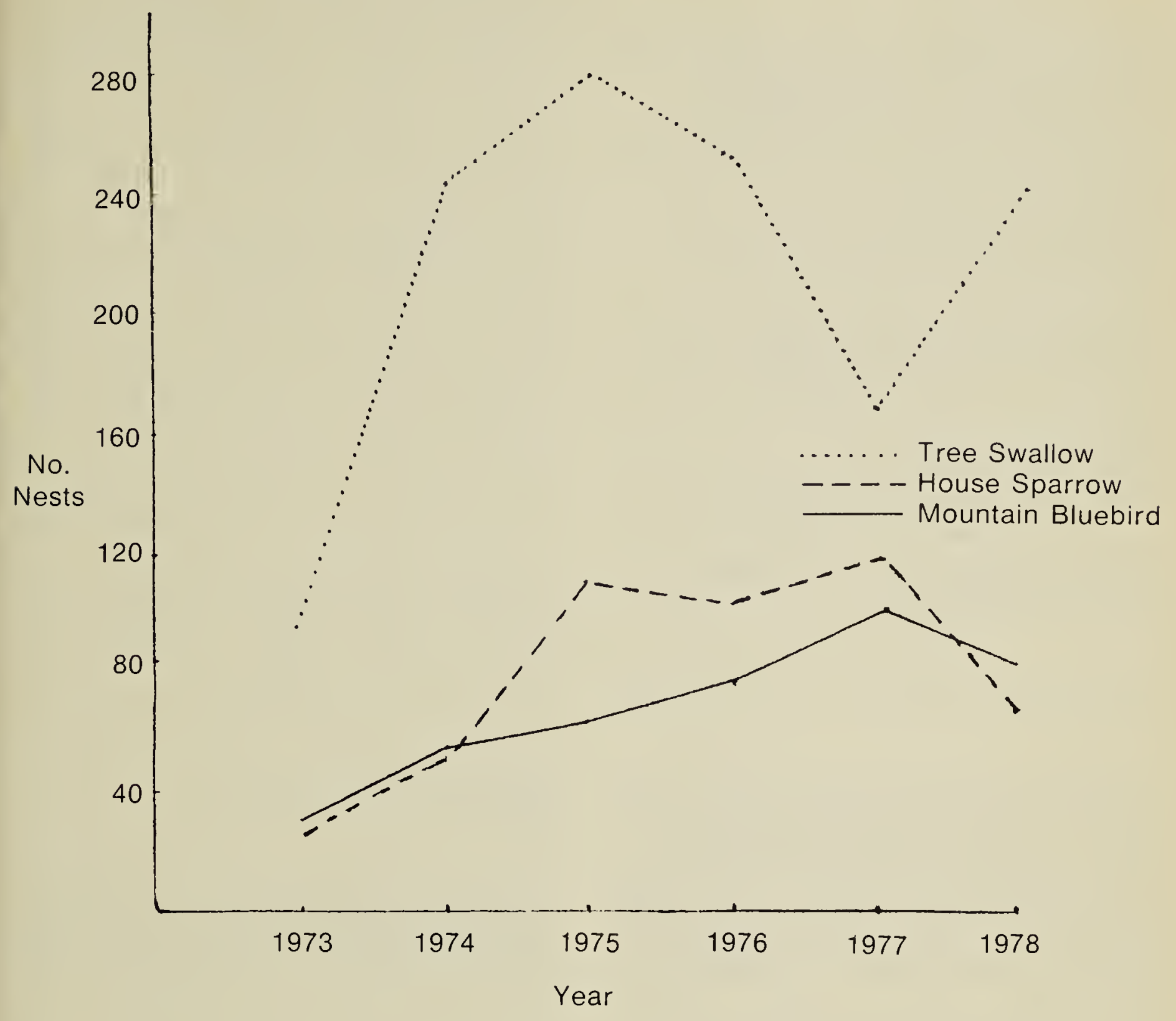

Uchida showed a $46 \%$ return of adults banded the previous year in his 3-year study of two species of swallows in Japan. ${ }^{15}$

The above figures illustrate the tendency of Tree Swallows to return to their natal territory or environs and is termed site attachment or place faithfulness. This attachment to a place is further illustrated by the distances recorded from banding site to recapture site. The 27 adult Tree
Swallows that were recaptured averaged $3.17 \mathrm{~km}$ from the point of banding, with 16 of the recaptured adults being within $1.6 \mathrm{~km}$ or 2 birdhouses of the place where they were banded. This average of 3.17 $\mathrm{km}$ would be considerably less if the longest retrapped distance of $20 \mathrm{~km}$ by bird 880-40783 was disregarded due to apparent disturbance by the author. This bird was retrapped twice in 1977. On the first occasion, it was 
House Sparrow then Tree Swallow House Sparrow then Mt. Bluebird House Sparrow then House Wren Tree Swallow then House Sparrow Tree Swallow then Mt. Bluebird Tree Swallow then House Wren Mt. Bluebird then House Sparrow Mt. Bluebird then Tree Swallow Mt.Bluebird then House Wren House Wren then Tree Swallow House Wren then Mt. Bluebird House Wren then House Sparrow Black-capped Chickadee then House Wren

Mt. Bluebird then Tree Swallow then Mt. Bluebird

House Sparrow then Tree Swallow then House Sparrow

TOTALS:

$\begin{array}{rrrrrrr}1973 & 1974 & 1975 & 1976 & 1977 & 1978 & \text { Total } \\ 5 & 11 & 18 & 12 & 21 & 7 & 74 \\ 1 & - & 1 & 1 & 1 & 1 & 5 \\ 1 & 1 & 2 & 1 & - & - & 5 \\ - & 4 & 3 & 2 & 4 & - & 13 \\ 2 & 1 & - & - & - & - & 3 \\ 1 & 3 & 2 & - & 3 & - & 9 \\ - & 1 & 3 & - & 1 & - & 5 \\ 2 & 4 & 9 & 19 & 27 & 8 & 69 \\ 2 & - & 1 & - & - & - & 3 \\ - & - & - & - & - & - & 0 \\ - & - & - & - & - & - & 0 \\ - & - & - & - & - & 0 & 0 \\ 1 & - & - & - & - & - & 1 \\ - & - & - & 1 & 1 & - & 2 \\ - & - & - & - & 2 & - & 2 \\ 15 & 25 & 39 & 36 & 60 & 16 & 191\end{array}$

minimum of 4 years old.

The 11 nestling Tree Swallows that were recaptured travelled an average distance of $20 \mathrm{~km}$ to nest from the nesting only $1.6 \mathrm{~km}$ from the box it was banded in, but a month later, it was retrapped $20 \mathrm{~km}$ from the original banding place. Two birds banded as adults in 1976 were recaptured in 1979, making them a

TABLE 3 - Quantitative Summary of Banding Data

Year

Mountain 1976

Bluebird

Tree $\quad 1976$

Swallow
Banded

1977

TOTAL:

1977

Age

Adult

Nestling

Adult

Nestling

Adult

Nestling

Adult

Nestling

TOTAL:
No.

No. Retrapped

Banded

1977

No.

Retrapped

1978

Retrapped

1979

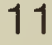

73

42

217

342

89

520

108

302

1,019

$\begin{array}{rrr}3 & 0 & 0 \\ 1 & 0 & 0 \\ - & 2 & 1 \\ - & 0 & 0 \\ 4 & 2 & 1 \\ 8 & 3 & 2 \\ 3 & 5 & 0 \\ - & 11 & 3 \\ - & 1 & 2 \\ 11 & 20 & 7\end{array}$


box in which they were born. An interesting question is why were there only 11 nestling returns out of 822 nestlings banded. Part of the answer is no doubt higher mortality among young than adults. Perhaps the survivors spread indiscriminately throughout their natural range and only by chance return to their natal area, as suggested by Lincoln. ${ }^{7}$ This theory does not seem to be true as it applies to Tree Swallows. If it was, then how come people with established trails in Hinton and Edmonton, Alberta, and throughout Saskatchewan and Manitoba are not recovering birds banded by me, and vice versa? It was not until Andrew Stiles developed a trail just north of my northeastern section that I started to get returns other than from my trail. On top of this, all the banded birds that showed up in Andrew's boxes were from the northeastern section of my trail. Of the 11 nestling returns, 6 were the result of Andrew's trail with distances travelled by the nestlings of $8.8,11.2,16,17.6,19.2$, and $97.6 \mathrm{~km}$ being recorded. There was only one instance of an adult bird (850-98458) moving from my trail to Andrew's trail or vice versa. All this information indicates that the young Tree Swallows coming north on migration to breed return to their natal site, and then radiate out from these to the nearest available nesting sites in response to the pressure and greater territorial dominance of the older birds.

Although the recovery data for Mountain Bluebirds was much less comprehensive, the same general trend appears to apply. Of the 7 recaptures, 6 were adults recovered an average of $0.4 \mathrm{~km}$ from the point of banding, and only one nestling was recaptured, $14.4 \mathrm{~km}$ from the nest in which it was banded. (Includes one bird from Dan Sikorski's trail.)
'CHAPMAN, L. B. 1935. Studies of a Tree Swallow colony. Bird-Banding 6:4557.

${ }^{2}$ CHAPMAN, L. B. 1955. Studies of a Tree Swallow colony. Bird-Banding 26:4570.

${ }^{3}$ ERSKINE, A. J. 1964. Nest site competition between Bufflehead, Mountain Bluebird and Tree Swallow. Canadian Field-Naturalist 78:202-203.

${ }^{4}$ HAARTMAN, L. von. 1957. Adaptation in hole-nesting birds. Evolution 11:339347.

${ }^{5}$ HOLROYD, G. L. 1975. Nest site availability as a factor limiting population sizes of swallows. Canadian Field-Naturalist 89:60-64.

${ }^{6}$ HOUSTON, D. V. 1973. 1972 Best year yet for Saskatoon bluebird house trail. Blue Jay 31:35.

${ }^{7}$ LINCOLN, F. C. 1934. The operation of homing instinct. Bird-Banding 5:149155.

${ }^{8}$ LOW, S. H. 1934. Nest distribution and survival ratio of Tree Swallows. BirdBanding 5:24-30.

${ }^{9}$ PINEL, H. W. and C. J. ROBINSON. 1974 Calgary bluebird trail. Blue Jay 32:108-110.

${ }^{10}$ PINEL, H. W. and C. J. ROBINSON. 1975. Calgary bluebird trail - 1974. Blue Jay 33:50-52.

"PINEL, H. W. and C. J. ROBINSON. 1976. Calgary bluebird trail -1975 . Blue Jay 34:54.

${ }^{12}$ PINEL, H. W. 1977. Calgary bluebird trail - 1976. Blue Jay 35:43-44.

${ }^{13}$ PINEL, H. W. and J. R. RIDDELL. 1978. Calgary bluebird trail - 1977. Blue Jay $36: 44$.

${ }^{14}$ PINEL, H. W. and J. R. RIDDELL. 1979. Calgary bluebird trail - 1978. Blue Jay 37:51-52.

${ }^{15}$ UCHIDA, S. 1932. Studies of swallows by the banding method. BirdBanding 3:1-11.

${ }^{16}$ WHITTLE, C. L. 1926. Notes on the nesting habits of Tree Swallows. Auk 43:247. 